\title{
The replacement of tradiocional lamps by LED in Brazil: a case of environmental and economic sustainability (short review)
}

\begin{abstract}
Background: In Brazil, at the time of the energy crisis in 2001, in order to save energy consumed by lamps, a compact fluorescent lamp was introduced in the market, which was well accepted in terms of illumination and cost. However, through technological advances, since 2015, the government recommended lamps of LED for energy saving. It is also considered that the ease in disposing of these bulbs after their useful life is a particularly relevant factor for the environment. The objective of this work is to demonstrate an example of economic gain with the exchange of old incandescent, halogen and fluorescent lamps by LED. As conclusion, it was verified that with the insertion of the LED in the Brazilian market, gains were obtained in several sectors such as: the reduction of waste production (the LED lamp has a much longer life cycle than the others) and the reduction of energy waste (reduction in the use of the national energy matrix)
\end{abstract}

Keywords: LED lamps, Brazilian technical standards, reduction in energy consumption, residential electrical installations
Volume 5 Issue I - 2019

\author{
Vanessa Meloni Massara \\ Department of Adjunct Researcher, Polytechnic School, \\ University of São Paulo, Brazil
}

Correspondence: Vanessa Meloni Massara, Department of Adjunct Researcher, Polytechnic School, University of São Paulo, Brazil,Tel+55I I 97567 9973,Email vmmassara@usp.br

Received: January 30, 2019 | Published: February 18, 2019

\section{Introduction}

The Brazilian government considers as environmental advantages of LED lamps: they don't contain mercury (such as compact fluorescents); the absence of heavy metals is relevant to human health and the environment during its use and when the lamp is discarded. It is considered a correct lamp throughout its life cycle (from manufacturing to disposal): it consumes little energy to produce and low energy when in use, helping to conserve natural resources, the basis of the concept of sustainability. Because it has a longer useful life, it is discarded less frequently, generating less waste for disposal in landfills. By not emitting ultraviolet and infrared rays they don't harm the skin in continuous exposure. They are more resistant than other bulbs, being very difficult to break, but if this occurs, it has a coating that prevents the chips from spreading while preserving the user's health and safety. ${ }^{1}$ The LED doesn't attract insects, minimizing the issues associated with their combat and offers advantages of comfort (visual and in the environment), since they don't emit ultraviolet and infrared radiation, thus being more comfortable to the eyes. Technological advantages considered by the Brazilian market are also several. The LED has a very small light dimension. This contributes to a high optical control because it is simpler to develop a system for a light output point. ${ }^{2}$ As LED don't emit light in all directions (such as conventional lamps), it contributes to a better targeting of the light beam, concentrating it and with less loss of luminous flux by the internal reflections of the human optical system. Because LED has small dimensions, it allows a more flexible design of the luminaries. Many LED bulbs are manufactured in the same shape and nozzle as conventional bulbs, making it easy to replace them, without affecting lighting fixtures and electrical installation already existing, reducing the initial investment costs and adapting the installation and luminaries.

This type of lamp has immediate lighting; the number of times and the frequency at which it is turned on and off doesn't change its useful life. ${ }^{3}$ Since June 30, 2016, the Federal Government has banned the sale of incandescent bulbs in Brazilian territory. But the most relevant benefits to society as a whole with the use of LED are economic and are addressed in this article in a brief example. ${ }^{4}$

\section{Methods}

As an example, this article demonstrates the replacement of traditional (incandescent and fluorescent) by LED lamps in a house with 20 light points (in total) without distinction of power between the rooms (i.e., all points of light will use a bulb with the same power). The light points are shown in Figure 1.

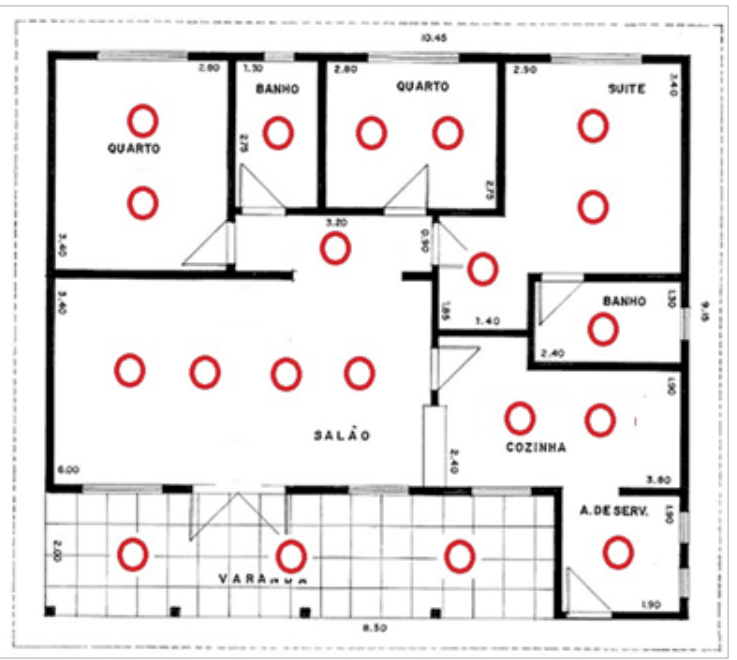

Figure I Generic plant to demonstrate the economic viability of LED lamps in Brazil.

The lamps used in the study have the characteristics expressed in Table 1. 
Table I Characteristics of the lamps compared in this study

\begin{tabular}{lllll}
\hline Type of lamp & $\begin{array}{l}\text { Average lamp } \\
\text { price (US\$) }\end{array}$ & $\begin{array}{l}\text { Total number of bulbs needed } \\
(\mathbf{2 0 *} \text { price) } \mathbf{( U S} \$)\end{array}$ & $\begin{array}{l}\text { Shelf life } \\
\text { (hours) }\end{array}$ & $\begin{array}{l}\text { Lamp power due to } \\
\text { the lumen }\end{array}$ \\
\hline incandescent & 13,02 & 260,40 & 1.2 & 60 \\
LED & 52,08 & 1041,60 & 25 & 10 \\
compact florescent & 39,06 & 781,2 & 8 & 15 \\
halogen & 27,84 & 556,80 & 1.5 & 70 \\
\hline
\end{tabular}

Note: considering the dollar R \$ 3.72 (Brazilian currency) on Jan, 29, 2019; lamp prices based values in Jan, 2019. Other considerations used for the comparison of economy:

a. consumption of 6 hours / day; a month of 30 days;

b. the tariff considered is the one in force in Greater São Paulo in January 2019: c. rate of use of the distribution system (residential consumption simples class, low voltage): $\mathrm{R} \$ / \mathrm{kWh} 0.21276^{4}$ (Brazilian currency);

d. energy tariff (TE): R $\$$ kWh 0, 270874 (Brazilian currency);

e. The total is the sum of both rates. The calculation of the monthly electricity bill considering each type of lamps is shown in Table 2.

Table 2 Calculation of the Monthly Account in function of the power and the consumption

\begin{tabular}{|c|c|c|c|c|c|}
\hline Type of lamp & $\begin{array}{l}\text { Daily consumption } \\
\text { (hours) }\end{array}$ & $\begin{array}{l}\text { Monthly } \\
\text { consumption (hours) }\end{array}$ & $\begin{array}{l}\text { Monthly consumption } \\
\text { (KWh) }\end{array}$ & $\begin{array}{l}\text { Rate (dollars/ } \\
\text { kWh) }\end{array}$ & $\begin{array}{l}\text { Monthly bill } \\
\text { (US\$) }\end{array}$ \\
\hline incandescent & 6 & 180 & 216 & 1,80 & 388,6 \\
\hline LED & 6 & 180 & 36 & $\mathrm{I}, 80$ & 64,8 \\
\hline compact florescent & 6 & 180 & 54 & $\mathrm{I}, 80$ & 97,2 \\
\hline halogen & 6 & 180 & 252 & 1,80 & 453,6 \\
\hline
\end{tabular}

Note: considering the dollar R \$ 3.72 (Brazilian currency) on Jan, $29,2019$.

\section{Results}

\section{Using the expressions}

Monthly consumption is expressed as (kWh):

(Number of points (lamps), *Lamp power (W) Number of hours (per month) that are connected) $/ 1000$

The monthly bill is expressed by (US\$): Monthly consumption, *Energy utility tariff.

The payback in months considers two calculations. The gain in the monthly bill using the LED:

I. Monthly Gain=LED Bill-Incandescent (or fluorescent or halogen) bill;

II. the investment in replacement of other lamps by LED:

III. Initial investment=Total purchase value of LED bulbs-Total purchase price of incandescent bulbs (or fluorescent bulbs or

$$
\text { halogen bulbs) }
$$

IV. It could be considered as initial investment only the value of LED bulbs. However, given the wide useful life span between types of lamps, it was considered that, in any case, there would already be a type of lamp installed which also had its initial cost (and needs to be changed much more frequently than LED). Therefore, it was decided to subtract between the initial investment of the LED and the investment already made with the other types of lamp (which obviously reduces the initial investment of the LED and consequently its time of return due to the savings in the account of light).

V. Pay back = Monthly gain (compared to each type of lamp) Initial investment. Monthly gain=Difference between the values of the monthly accounts in relation to the monthly account with the use of the LED.

VI. The result is shown in Table 3.

VII. Note: total of lamps $=20$; Considering the dollar $\mathrm{R} \$ 3.72$ (Brazilian currency) on Jan, 29, 2019; Lamp prices based values in Jan, 2019.

Table 3 Calculation of pay back relating investment in the purchase of lamps and reduction in energy consumption using LED

\begin{tabular}{lll}
\hline Type of lamp & $\begin{array}{l}\text { Difference between accounts in the purchase } \\
\text { of the lamps in relation to LED (US\$) }\end{array}$ & $\begin{array}{l}\text { Difference between the values investments in the } \\
\text { purchase of the lamps in relation to LED (US\$) }\end{array}$ \\
\hline Incandescent & 323,80 & $\begin{array}{l}\text { Payback } \\
\text { (months) }\end{array}$ \\
compact florescent & 32,40 & 260,40 \\
Halogen & 388,80 & 484,40 \\
\hline
\end{tabular}




\section{Discussion}

The fluorescent lamp is the one that comes closest to the LED in terms of both the technical characteristics and the value of power and price of the lamp, which is less economically beneficial (both have similar powers for similar illuminances and consequently similar energy consumption). As for the other two bulbs (incandescent and halogen) that require high power values compared to the LED, it is very advantageous to replace them, because the savings in the light bill quickly compensate for the price difference between the different bulbs.

\section{Conclusion}

The use of the LED lamp is associated with its longer life and lower power required for a luminous flux and luminance similar to the others. It has a number of advantages, which make clear the environmental benefits of its use. It is a fact that its initial investment is more expensive when compared to the others, requiring a few months for the return of the value used in the substitution, however the reduction in energy consumption and consequent reduction in the light bill have an advantage that extends over its long service life. Its technological development should add in a medium-term, technical improvements and adaptation that must make its use common in the
Brazilian market. With the expansion of its use there should be a reduction in its price which will make its replacement more attractive, thus determining, its definitive entry into the lighting market of the country.

\section{Acknowledgments}

None.

\section{Conflicts of interest}

Author declares that there is no conflict of interest.

\section{References}

1. National institute of metrology, quality and technology-in metro. LED lamps. 2016.

2. Bley FB. LEDs vs. Conventional Lamps - Enabling Switching. Revisto Especialize. 2012.

3. Ferreira AR. Solid state lighting, potential energy savings for the country. Santo André, Thesis (master degree), Electrical Engineering, Federal University of $A B C .2014$

4. Enel. Electricity tariff in São Paulo. 2019. 